\title{
SOBRE O PROJETO KANTIANO DE UMA FILOSOFIA TRANSCENDENTAL
}

\author{
Juan A. Bonaccini*
}

\begin{abstract}
RESUMO
É sabido que a Crítica da razão pura apresenta uma estrutura arquitetônica bastante peculiar. No entanto, o que nem sempre é notado é que essa estrutura está intrinsecamente ligada à sua estratégia argumentativa. $\mathrm{Na}$ verdade, para justificar a ideia de Filosofia Transcendental como a melhor solução disponível para o problema do conhecimento metafísico levantado por uma crítica da razão pura, Kant defende que é preciso encontrar um lugar específico e justificável para um conhecimento a priori na metafísica. Mas isso só pode ser feito ao abandonarmos a pretensão ao conhecimento de objetos a priori e abraçarmos a noção de conhecimento a priori da forma de objetos empíricos. Nesse sentido, o artigo reconstrói a ideia geral, a estratégia argumentativa e do quadro metodológico da primeira Crítica como um programa para a metafísica como filosofia transcendental. Também sugere-se que a crítica funciona como uma teoria geral de um conhecimento a priori, a saber, como uma metateoria do conhecimento racional que dá conta das condições não empíricas mais gerais dos objetos e da experiência.
\end{abstract}

Palavras-chave: Kant. Filosofia transcendental. Metafísica. Metateoria. Conhecimento a priori.

\begin{abstract}
It is well known that the Critique of pure reason presents quite a peculiar architectural structure. Yet, it is not always noticed that this is intrinsically connected to its argumentative strategy. Indeed, to justify the very idea of Transcendental Philosophy as the best available solution to the problem of metaphysical knowledge, Kant argues that one needs to find a specific
\end{abstract}

\footnotetext{
* Doutor em Filosofia pela Universidade Federal do Rio de Janeiro, com bolsa de doutorado Sanduíche na Albert Ludwigs-Universität Freiburg (CNPq/1996). Professor Titular do Departamento de Filosofia da Universidade Federal de Pernambuco e do Programa Integrado de Doutorado em Filosofia (UFRN/UFPB/UFPE).

E-mail: juan.bonaccini@ufpe.br.
} 
and justifiable place for a priori knowledge in metaphysics. This can only be accomplished by abandoning the claim to knowledge of pure entities beyond experience and embracing the notion of a priori knowledge of the form of empirical objects. Accordingly, the paper reconstructs the general idea, the argumentative strategy and the methodological framework of the first Critique as a program for metaphysics as transcendental philosophy. It also suggests that the Critique operates as a general theory of a priori cognition, viz. as a meta-theory of rational knowledge that gives account for the most general and fundamental non-empirical conditions of objects and experience.

Keywords: Kant. Transcendental Philosophy. Metaphysics. Meta-theory. A priori knowledge.

\section{Introdução}

É sabido que a Crítica da razão pura apresenta uma estrutura argumentativa bastante peculiar. O que nem sempre se leva em consideração, todavia, é que essa estrutura define a maneira como Kant coloca seu problema filosófico central e sua proposta de solução. Nesse sentido, cada uma de suas partes deve ser compreendida como um passo da argumentação geral que justifica sistematicamente a proposta da Filosofia Transcendental como a melhor solução disponível para o problema do conhecimento metafísico exposto por uma crítica da razão. Visando a uma reconstrução preliminar desse programa, o que ofereceremos aqui é somente uma interpretação geral da ideia central, da estratégia argumentativa e da estrutura metódica da Crítica da razão pura, a fim de precisar o lugar do conhecimento a priori e o caráter específico da Crítica como uma teoria da cognição a priori, a saber, como ciência meta-teórica de todo o conhecimento racional.

Há na verdade um detalhe essencial no modo como Kant entende "conhecimento racional", diferente dos matemáticos e dos metafísicos da época: Kant não entende conhecimento racional (i. é, "puro"), como um conhecimento de objetos puros, mas antes como um conhecimento puro de objetos. Por isso, sua ideia central é a de que a razão não pretenderia conhecer nenhum objeto "puro", mas poderia em princípio aplicar ou construir certas "estruturas" de percepção, compreensão e concepção 
no ato de conhecer qualquer objeto, propriedade ou estado de coisas da experiência. Essas estruturas funcionariam como formas que já sempre devem estar pressupostas em toda percepção, intelecção ou concepção como suas condições; como condições não-empíricas de tudo que é empírico. Esse conhecimento, também chamado "transcendental", não seria um conhecimento a priori por ser conhecimento de objetos a priori, mas antes por ser um conhecimento a priori da forma lógica dos objetos empíricos, "impuros" por definição. Esse seria o verdadeiro objeto da metafísica, pelo menos do ponto de vista teórico.

\section{A ideia central e a estratégia de uma Crítica da Razão Pura}

De modo simples: o problema fundamental de Kant consiste em determinar se é possível conhecimento científico inteiramente a priori. A saber: se a Metafísica é capaz de conhecimento puro, mas objetivo, e em que medida ${ }^{1}$. O contexto, portanto, é o de uma ciência em crise $^{2}-$

1 Veja-se Crítica da razão Pura, A2-3/B2-3ss (doravante KrV, citada conforme a convenção da Kant-Forschung, pelo número da página no original, precedido das letras A ou B, que indicam respectivamente a paginação da primeira ou segunda edições), e confronte-se com Prolegomena, AA 04: 275ss [Todas as obras de Kant, exceto a $\mathrm{KrV}$, são citadas com as letras AA, que abreviam a expressão Akademie-Ausgabe, i.é, edição da Academia Alemã das Ciências, seguidas do número do volume, dois pontos e o número das páginas]. Veja-se também o prefácio à primeira edição $(\mathrm{A})$, onde Kant define com extrema clareza a natureza de sua Crítica como uma espécie de tribunal cujo desígnio consistiria em investigar a possibilidade do conhecimento a priori, seu alcance e seus limites mediante um exame da própria faculdade de conhecimento, a fim de ajuizar as pretensões da metafísica de acordo com leis racionais, eternas e imutáveis. Com efeito, a KrV deve “(...) das beschwerlichste aller ihrer Geschäfte, nämlich das der Selbsterkenntniß, aufs neue zu übernehmen und einen Gerichtshof einzusetzen, der sie bei ihren gerechten Ansprüchen Scherer, dagegen aber alle grundlose Anmaßungen nicht durch Machtsprüche, sondern nach ihren ewigen und unwandelbaren Gesetzen abfertigen könne; und dieser ist kein anderer als die Kritik der reinen Vernunft selbst. (...) nicht eine Kritik der Bücher und Systeme, sondern die des Vernunftvermögens überhaupt in Ansehung aller Erkenntnisse, zu denen sie unabhängig von aller Erfahrung streben mag, mithin die Entscheidung der Möglichkeit oder Unmöglichkeit einer Metaphysik überhaupt und die Bestimmung sowohl der Quellen, als des Umfanges und der Gränzen derselben, alles aber aus Principien" (KrV AXI-XII). Sobre os termos "puro" e "a priori" veja-se a nota 10.

2 Veja-se o prefácio à primeira edição $(\mathrm{A})$, sobretudo KrV AVIIss (“...Es war eine Zeit, in welcher sie die Königin aller Wissenschaften genannt wurde...”), e compare-se com $\mathrm{KrV}$ BXIVss. Veja-se, ainda, os Prolegomena, §§4ss (AA 04:271ss). 
já que perguntar pela possibilidade do conhecimento a priori pressupõe duvidar-se da "realidade" da metafísica como empresa científica ${ }^{3}$. Com efeito, dado que a pretensão da Metafísica a um conhecimento a priori é muitas vezes posta em dúvida, Kant sabe que é preciso responder ao desafio ou reconhecer que aquela não se sustenta sobre uma base sólida. Por isso, Kant apresenta uma determinada interpretação do problema e uma alternativa para solucioná-lo.

A metafísica sempre ergueu a pretensão a um conhecimento além da experiência (a saber, a um conhecimento a priori, puramente racional) ${ }^{4}$, mas essa pretensão poderia em princípio ser entendida de duas maneiras: como um "conhecimento de objetos puros" 5 ou como um "conhecimento puro de objetos" ${ }^{6}$. Se a primeira é posta em dúvida, a segunda promete

3 " $\mathrm{Zu}$ fragen, ob eine Wissenschaft auch wohl möglich sei, setzt voraus, daß man an der Wirklichkeit derselben zweifle" (Prolegomena, AA 04: 256).

4 Veja-se, por exemplo, KrV Vorrede, AVII e BXIV-XX; B19-24; A841s/B869s. Vejase também Prolegomena, AA 04:265-6: “(...) was die Quellen einer metaphysischen Erkenntniß betrifft, so liegt es schon in ihrem Begriffe, daß sie nicht empirisch sein können. Die Principien derselben (wozu nicht blos ihre Grundsätze, sondern auch Grundbegriffe gehören) müssen also niemals aus der Erfahrung genommen sein: denn sie soll nicht physische, sondern metaphysische, d.i. jenseit der Erfahrung liegende, Erkenntniß sein. (...) Sie ist also Erkenntniß a priori, oder aus reinem Verstande und reiner Vernunft. (...) also reine philosophische Erkenntniß heißen müssen (...)”. Cf. ainda Prol, AA 04:365ss.

5 A inspiração dessa alternativa inviável derivaria do entusiasmo provocado pelo conhecimento puro na Matemática (que de certo modo poderia ser visto como um conhecimento de "objetos a priori": números, figuras geométricas, fórmulas, etc), mas os metafísicos se esqueceriam de que conhecimentos matemáticos são construídos na intuição. Veja-se, por exemplo, KrV A 4-5/B8-9; A 712/B740.

6 Kant usa essa expressão reiteradas vezes. Por exemplo, na Introdução à Crítica: “,Diese Untersuchung, die wir eigentlich nicht Doctrin, sondern nur transcendentale Kritik nennen können, weil sie nicht die Erweiterung der Erkenntnisse selbst, sondern nur die Berichtigung derselben zur Absicht hat und den Probirstein des Werths oder Unwerths aller Erkenntnisse a priori abgeben soll, ist das, womit wir uns jetzt beschäftigen. Eine solche Kritik ist demnach eine Vorbereitung wo möglich zu einem Organon, und wenn dieses nicht gelingen sollte, wenigstens zu einem Kanon derselben, nach welchem allenfalls dereinst das vollständige System der Philosophie der reinen Vernunft, es mag nun in Erweiterung oder bloßer Begrenzung ihrer Erkenntniß bestehen, sowohl analytisch als synthetisch dargestellt werden könnte. Denn daß dieses möglich sei, ja daß ein solches System von nicht gar großem Umfange sein könne, um zu hoffen, es ganz zu vollenden, läßt sich schon zum voraus daraus ermessen, daß hier nicht die Natur der Dinge, welche unerschöpflich ist, sondern der Verstand, der über die Natur der Dinge urtheilt, und auch dieser wiederum 
uma solução racional e duradoura ${ }^{7}$ : a metafísica não pode se arrogar um conhecimento de objetos puros, mas sim um conhecimento puro de objetos $^{8}$. Assim, o que à primeira vista pode dar a impressão de um mero deslocamento gramatical do termo ("puro"), acarreta na verdade uma diferença radical na abordagem conceitual do problema9. No primeiro caso, inspirada pelo sucesso das matemáticas, a razão pretenderia conhecer objetos que não podem ser dados na experiência (como, por exemplo, no caso de ideias platônicas, ideias inatas cartesianas, mônadas leibnizianas, ideias de substâncias lockianas, etc.); "objetos" que por definição não podem ser objeto de percepção, porquanto ultrapassam os limites da nossa capacidade: trata-se de "objetos" a priori ou $\operatorname{puros}^{10}$. No segundo caso, a

nur in Ansehung seiner Erkenntniß a priori den Gegenstand ausmacht (...)" (KrV B26) (o sublinhado é nosso). Cf. B XXss, XXVss.

7 Kant sugere que a metafísica como elaborada até então conduz a um impasse. Nesse sentido, refere-se logo de saída às contradições provocadas pela metafísica como a uma espécie de sintoma de sua inviabilidade (AVIII, B XXss, BXXXVIII). Em B19ss, por exemplo, Kant parece indicar que constituem o problema da metafísica que a $\mathrm{KrV}$ deve resolver: "Daß die Metaphysik bisher in einem so schwankenden Zustande der Ungewißheit und Widersprüche geblieben ist, (...)ist lediglich der Ursache zuzuschreiben, daß man sich diese Aufgabe (...) nicht früher in Gedanken kommen ließ. Auf der Auflösung dieser Aufgabe, oder einem genugthuenden Beweise, daß die Möglichkeit, die sie erklärt zu wissen verlangt, in der That gar nicht stattfinde, beruht nun das Stehen und Fallen der Metaphysik (...). Da sich aber bei allen bisherigen Versuchen, diese natürliche Fragen, z.B. ob die Welt einen Anfang habe, oder von Ewigkeit her sei u.s.w., zu beantworten, jederzeit unvermeidliche Widersprüche gefunden haben, so kann man es nicht bei der bloßen Naturanlage zur Metaphysik, d.i. dem reinen Vernunftvermögen selbst, woraus zwar immer irgend eine Metaphysik (es sei, welche es wolle) erwächst, bewenden lassen, sondern es muß möglich sein, mit ihr es zur Gewißheit zu bringen, entweder im Wissen oder Nicht-Wissen der Gegenstände, d.i. entweder der Entscheidung über die Gegenstände ihrer Fragen, oder über das Vermögen und Unvermögen der Vernunft in Ansehung ihrer etwas zu urtheilen, also entweder unsere reine Vernunft mit Zuverlässigkeit zu erweitern, oder ihr bestimmte und sichere Schranken zu setzen. Diese letzte Frage, die aus der obigen allgemeinen Aufgabe fließt, würde mit Recht diese sein: Wie ist Metaphysik als Wissenschaft möglich?" (o destaque em itálico é de Kant).

8 Veja-se, por exemplo, BXVII-XIX.

9 É precisamente isso que vai permitir posteriormente distinguir com rigor o predicado "transcendente" do predicado "transcendental", já que um conhecimento metafísico de objetos puros é transcendente, mas um conhecimento puro de objetos não.

10 Ainda que os termos "a priori" e "puro" possam ser distinguidos, já que nem sempre algo a priori é "puro a priori", uso os termos indistintamente, salvo indicação, tal como Kant: 
razão não pretenderia conhecer nenhum objeto "puro", mas poderia em princípio aplicar ou construir certas "estruturas" de percepção, intelecção e concepção no ato de conhecer qualquer objeto, propriedade ou estado de coisas no âmbito da experiência ${ }^{11}$. O conhecimento dessas "estruturas" seria um conhecimento a priori: ao refletir-se sobre a experiência e verificar-se que dentre seus elementos existem alguns que não poderiam derivar da própria percepção, no sentido de que não podem ser imputados a dados sensoriais ou a suas causas, seria possível vislumbrar-se que há certas formas que já devem sempre ser pressupostas em toda percepção, intelecção ou concepção como suas condições ${ }^{12}$.

Por um lado, essas estruturas constituiriam per se certo tipo de "conhecimento racional", enquanto contribuição a priori de nossas faculdades ao processo da cognição ${ }^{13}$. Por outro, Kant parece sugerir que

"Es heißt aber jede Erkenntniß rein, die mit nichts Fremdartigem vermischt ist. Besonders aber wird eine Erkenntniß schlechthin rein genannt, in die sich überhaupt keine Erfahrung oder Empfindung einmischt, welche mithin völlig a priori möglich ist." (KrV A11). Cf. B2-3. Esse sentido de a priori é, porém, ambíguo. Para P. Kitcher existiriam pelo menos três usos do termo: 1) o lógico (quando dizemos que um juízo é logicamente universal e necessário), 2) o psicológico (quando dizemos que algum elemento num juízo ou conceito não tem sua origem na experiência), e 3) o epistêmico (quando dizemos que um conjunto de proposições exprimem conhecimento sintético a priori) (Kitcher 1990, p.14ss).

11 Uso o termo "construção" neste caso (e noutros semelhantes), salvo indicação expressa, num sentido diverso do kantiano, a fim de indicar o modo como dados sensoriais e conteúdos em geral são condicionados, determinados e configurados pelas estruturas formais que presidem todo ato cognitivo em seres racionais finitos como nós. "Construção" (Construction), para Kant, é um termo que define o modo como a matemática pura se representa seus objetos (números, fórmulas, figuras, etc) na intuição pura. Sobre isso vejase sobretudo KrV, A712/B740ss; Prol. AA 04:267ss, 283ss; Logik (Jäsche), AA 09: 23. Veja-se também, A782s/B810s, sobre o modo como a intuição pura que está na base aos conceitos matemáticos serve de guia (Leitfaden) para a demonstração. Sobre a concepção kantiana da construção de conceitos na intuição, existe uma longa discussão na literatura. Veja-se, por exemplo, Parsons 1992, pp. 77ss; Falkenstein 1995, pp. 273-4; G. Bird 2006, pp. 137ss, 152ss, 426ss, 436ss, 742ss. Cf. H. Vaihinger, Kommentar II, p. 470-472.

12 Isso implica que a experiência fornece a ocasião para a aplicação de estruturas que descobrimos a partir de reflexão e isolamos mediante abstração. Cf. Metafísica Dohna (AA 28: pp. 615s). Veja-se também nosso trabalho: "Anotações sobre a Metafísica Dohna" (2007, p. 231ss).

13 Conforme canônica formulação de B1-2: "Denn es könnte wohl sein, daß selbst unsere Erfahrungserkenntniß ein Zusammengesetztes aus dem sei, was wir durch Eindrücke empfangen, und dem, was unser eigenes Erkenntnißvermögen (durch sinnliche Eindrücke 
também poderíamos ter um acesso, um conhecimento a priori acerca dessas "estruturas" mediante abstração; a saber, um conhecimento reflexivo e, portanto, de segunda ordem acerca dessas estruturas como condições nãoempíricas de tudo que é empírico ${ }^{14}$. Esse conhecimento, também chamado "transcendental", não seria um conhecimento a priori por ser conhecimento de objetos a priori, ou puros, enquanto seres inteligíveis ou meros entes de razão; seria antes um conhecimento puro, totalmente a priori, da forma dos objetos empíricos, "impuros" por definição.

Assim, muito embora a razão humana seja incapaz de um conhecimento puro de essências (i. é, de conhecimento a priori de "coisas em si mesmas" ${ }^{15}$ ), a Metafísica poderia mesmo assim ser capaz de conhecimento a priori. Antes robustecida que enfraquecida pela crise, a Metafísica seria doravante reerguida como uma ciência teórica acerca das "estruturas formais" que a razão humana construiria e aplicaria automaticamente ao perceber, conhecer, pensar e agir no mundo de sua experiência ${ }^{16}$. A questão central de uma Crítica da razão pura é justamente apresentar e defender essa sugestão; e, sobretudo (mas não apenas), aplicála ao que Kant chama uso teórico da razão, que abrange tanto a experiência vulgar e quotidiana do mundo enquanto mundo de objetos do pensamento e da percepção, como a experiência científica que reinterpreta esse mesmo mundo de objetos a partir de certos axiomas e leis ${ }^{17}$. A estrutura

bloß veranlaßt) aus sich selbst hergiebt, welchen Zusatz wir von jenem //B2// Grundstoffe nicht eher unterscheiden, als bis lange Übung uns darauf aufmerksam und zur Absonderung desselben geschickt gemacht hat" (o sublinhado é nosso).

14 Como é sabido, Kant nem sempre parece ter clara essa última diferença (entre as estruturas como elementos a priori e o conhecimento a priori que podemos ter sobre elas). Nesse sentido, ao obter conhecimento a priori dessas estruturas enquanto estruturas nãoempíricas, todavia, a Filosofia Transcendental seria uma ciência não-empírica do empírico. Sobre esse último aspecto veja-se: G. Prauss (1989) [1973], pp. 62-85. Veja-se também Vaihinger, Kommentar, vol. I, pp. 134ss; vol II, pp. 101-107.

15 Cf. BXIVss, BXVIIIss, BXXVIss. Em BXXIX: ,"(...) Kritik uns zuvor von unserer unvermeidlichen Unwissenschaft in Ansehung der Dinge an sich selbst belehrt, und alles, was wir theoretisch erkennen können, auf blosse Erscheinungen (...)”.

16 De sua experiência vulgar e de sua experiência científica. Bem como de sua experiência prática, técnica e estética, se levarmos em consideração o sistema das três críticas.

17 No que diz respeito ao que Kant chamará de uso prático, como Kant deixa claro já no prefácio (BXXIV-XXXV), pode admitir-se um certo tipo de "cognição" dos objetos puros 
argumentativa da Crítica da razão pura, em consequência, tem que ser interpretada nesse contexto.

\section{A Metafísica como Meta-ciência do conhecimento a priori}

Com efeito, trata-se de determinar a possibilidade ou impossibilidade de uma ciência metafísica a partir de um exame das fontes, do alcance e dos limites do conhecimento racional ${ }^{18}$. Isso significa: determinar se (e em que medida) as nossas faculdades cognitivas são capazes de obter algum conhecimento de modo absolutamente a priori (a saber, em abstração de tudo que podemos conhecer mediante observação, percepção e experiência). Para tanto, elabora-se uma nova ciência que investiga conceitualmente, conhece e estabelece a priori os princípios universais que presidem tanto a experiência do mundo como um mundo de objetos, como seu conhecimento em todas e cada uma das ciências; analogamente ao modo como a geometria conhece o espaço e estabelece a priori seus axiomas e teoremas, ou como a física clássica demonstra a existência de leis que permitem conhecer a priori as relações e o comportamento de todos os fenômenos passíveis de movimento a partir de suas causas. Assim, enquanto ciência meta-teórica do conhecimento racional a priori, a Crítica apresentará uma teoria da percepção a priori dos objetos (Estética), uma teoria dos conceitos e juízos a priori que se referem diretamente a objetos (Analítica), uma teoria das inferências e dos conceitos a priori que não se referem diretamente a objetos (Dialética), bem como uma teoria da ciência e do método (que é a segunda e última parte da Crítica da razão pura).

De modo que Kant precisa mostrar tanto para os metafísicos como para seus adversários que a Metafísica pode ser levada a cabo como uma

da velha metafísica, destinados a operar como princípios racionais de ação. Assim, o que no uso teórico a razão não pode conhecer, não constituiria apenas um resultado negativo da investigação crítica, mas teria o lado positivo de colocar as idéias da razão em seu devido lugar, limitando as pretensões da sensibilidade e garantindo a viabilidade de um uso prático da razão pura. Nesse sentido, a observação é enfatizada com o conhecido slogan de Kant: "Ich mußte also das Wissen aufheben, um zum Glauben Platz zu bekommen "(BXXX). Veja-se ainda a segunda crítica (Kritik der praktischen Vernunft, Vorrede: AA 05:3ss; e, sobretudo, 05:50ss).

18 Cf. AXII. 
disciplina científica. Mas não no sentido de um conhecimento de objetos "a priori" (também chamado de transcendente), e sim como conhecimento a priori dos objetos da experiência (i. é, o conhecimento "transcendental" de suas condições de possibilidade). Precisa, portanto, partir de algo que todos aceitem para mostrar que pressupõe necessária e universalmente a aplicação dessas "estruturas racionais", cujo conhecimento é o verdadeiro objeto da ciência metafísica. Por isso, Kant parte da experiência vulgar e corriqueira, que tanto os metafísicos quanto seus detratores aceitam de bom grado: do fato de que temos percepções de objetos, daquilo que todo mundo aceita que se trata de uma experiência, a saber, um conhecimento dos objetos que existem no mundo. Feito isso, parte para a análise desse conhecimento primário e vulgar que constitui nossa experiência dos objetos que são ou podem ser objeto da percepção ${ }^{19}$.

19 Note-se nesse momento inicial (por exemplo, KrV B1-2, A19/B33) ainda não pode ser um problema saber se minhas percepções de objetos correspondem a objetos realmente existentes ou não (“...daran ist gar kein Zweifel...”, B1), porque em nossa experiência quotidiana, em que usamos nossa linguagem natural somos todos realistas: por mais metafísico ou antimetafísico que se possa ser, em circunstâncias normais ninguém duvida da existência dos objetos, quando tem percepções de um dia de sol ou de chuva, como ninguém põe em dúvida a existência de uma xícara de chá quente, que poderia ser como a que Kant tomou em Königsberg no dia 16 de maio de 1763 às 5:02 da manhã, como fazia todo dia, antes de fumar um cachimbo e sentar-se a escrever ou estudar, etc. Em B1 a tese realista precede como ponto de partida ao "fenomenalismo" que será defendido a partir das Conclusões (em A26/B42ss, e A32/B49ss): "Daß alle unsere Erkenntniß mit der Erfahrung anfange, daran ist gar kein Zweifel; denn wodurch sollte das Erkenntnißvermögen sonst zur Ausübung erweckt werden, geschähe es nicht durch Gegenstände, die unsere Sinne rühren und theils von selbst Vorstellungen bewirken, theils unsere Verstandesthätigkeit in Bewegung bringen, diese zu vergleichen, sie zu verknüpfen oder zu trennen, und so den rohen Stoff sinnlicher Eindrücke zu einer Erkenntniß der Gegenstände zu verarbeiten, die Erfahrung heißt? Der Zeit nach geht also keine Erkenntniß in uns vor der Erfahrung vorher, und mit dieser fängt alle an" (B1). Assim, também em KrV A19-20/B33-4, como antes em B1-2, Kant se compromete claramente com uma teoria causal da percepção ao definir a "intuição" (Anschauung) como conhecimento imediato de "objetos" e entender a sensação (Empfindung), que dará conteúdo à intuição empírica, como o efeito (Wirkung) da ação, da afecção desses "objetos" em sentido lato e ainda indeterminado (portanto, em termos de nossa experiência em linguagem natural). Essa tese realista fica mais clara ainda no $\S 3$ da terceira Crítica, na ideia de que a sensação pressupõe a presença real do objeto ("Wenn eine Bestimmung des Gefühls der Lust oder Unlust Empfindung genannt wird, so bedeutet dieser Ausdruck etwas ganz anderes, als wenn ich die Vorstellung einer Sache (durch Sinne, als eine zum Erkenntnißvermögen gehörige Receptivität) Empfindung nenne. Denn im letztern Falle wird die Vorstellung auf das Object, im erstern aber lediglich auf das 


\section{A análise, como Kant a entende, supõe a decomposição de uma representação em seus elementos constitutivos ${ }^{20}$. Por que decompor uma}

Subject bezogen (...)", AA 05:206). Outras passagens que a corroboram encontram-se, por exemplo, na Antropologia (AA 08: 153; 230s), e sobretudo nos Progressos (Fortschritte, AA 20:276): "Das Empirische aber, d.i. dasjenige, wodurch ein Gegenstand seinem Dasein nach als gegeben vorgestellt wird, heißt Empfindung (sensatio, impressio), welche die Materie der Erfahrung ausmacht (...)"(Ver também Vaihinger Kommentar II, 27). No entanto, o problema ulterior implicado pela tese fenomenalista de Kant torna-se patente e explícito, sobretudo, na "Refutação do Idealismo"; primeiro, no quarto paralogismo da edição A (A367ss), e depois, na nova versão mais "realista" da segunda edição (B274ss/ BXXXIXss), que pretende resolver o problema de um ponto de vista diverso daquele da edição A (sobre isso veja-se R. Landim Filho: "Descartes: 'idealista empírico e realista transcendental' ?" (1993, p. 313-343). O problema, a rigor, já estava latente no contexto da Dedução Transcendental, onde Kant parecia ter consciência dele e encará-lo, pelo menos em parte. De fato, é preciso notar que a Dedução parte da premissa de que tenho consciência de ter representações (Vorstellungen); e não prejulga que elas sejam representações que correspondem de fato a objetos realmente existentes no espaço fora de mim (pelo menos não em B131-2). Na primeira versão A da Dedução, a ordem da argumentação é diferente, mas o argumento nesse sentido é análogo, porque parte da chamada "síntese da apreensão" das representações, sem prejulgar sua origem (A 98: “...Vortellungen...mögen entspringen, woher sie wollen...”). Parte-se em ambos os casos da consciência de termos representações. Assim, a argumentação contra aqueles que põem na mesa o problema do mundo externo não pode aparecer na Crítica senão ulteriormente, porque o ponto de partida da ciência que quer provar a possibilidade da metafísica tem que ser um ponto pacífico (daí a teoria causal da percepção, que Kant parece aceitar em A1-2/B1, e em A19/B33). Outro modo de dizer isso seria lembrar que no começo, na introdução e no início da Estética, Kant argumenta contra os lockianos e os wolfianos, que aceitam essa experiência de objetos em sentido lato e corriqueiro, e somente depois, na Analítica, encara o desafio posto por Descartes, Berkeley e Hume. Como mostrei noutro lugar (Bonaccini, 2003), porém, essa premissa realista inviabiliza qualquer boa resposta para o problema do mundo externo tal como posto pelo ceticismo de alguns modernos (sobretudo o ceticismo acerca dos sentidos de Hume no fim do primeiro livro do Tratado, e o ceticismo radical postulado metodologicamente por Descartes na Meditatio prima). Confirmando nossa interpretação, pelo menos em parte, Graham Bird mostrou recentemente que a preocupação principal de Kant não é refutar um cético acerca do mundo externo, embora encare esse desafio na Refutação: "I have claimed that it is a mistake to see Kant's project in the Critique as directed centrally at the idealist challenge of the external world. Kant is concerned with that challenge in the Refutation of Idealism, but only as a part of his general attempt to construct a wider metaphysical inventory, a transcendental topic, of the basic a priori elements in experience. The aim is to construct more generally an accurate map of experience with which to correct the misconceptions of empiricists and rationalists, dogmatists and skeptics, as well as those of traditional idealists." (2006, p.763).

20 Sobre isso ver Caimi (2007, p. 21ss), que entende a análise como parte do método sintético. Para uma interpretação diferente do método sintético, ver por exemplo, G. Schönrich (1981, p. 56ss); Z. Loparic,(2000), p. 36ss/55ss; P. Kitcher (1990, p. 39). 
"representação"? Primeiro, porque é aquilo que nos é imediatamente dado na experiência, em nossa experiência ${ }^{21}$. Segundo, porque Kant e seus interlocutores, metafísicos ou não, todos consideram que conhecimento é representação, e toda a metafísica da época (quer preocupada com questões de justificação, quer não) parte de uma teoria da representação ${ }^{22}$. Assim, partindo das representações corriqueiras que consideramos como "experiências", "conhecimentos" ou "cognições" no sentido lato, ponto pacífico para todos, trata-se para Kant de analisar seus componentes básicos (seus "elementos"), e mostrar que dentre eles existem alguns que não são nem poderiam ser de caráter empírico (i. é, oriundos de percepções sensoriais). E então a teoria propõe-se a separar primeiro o componente "empírico" do "puro", a fim de poder isolar e tratar dos "elementos" a priori subjacentes em toda experiência ${ }^{23}$. Por isso Kant subdivide sua investigação, logo depois, numa teoria transcendental dos elementos, que ocupa quase toda a Crítica, e numa teoria transcendental do método, que ocupa a última parte restante ${ }^{24}$.

Por conseguinte, a "teoria transcendental dos elementos" do conhecimento é uma análise meta-teórica que parte do empírico, separa toda a matéria do conhecimento dada na percepção sensorial, e se concentra na análise das "estruturas" formais que presidem e organizam todo nosso conhecimento na experiência que temos do mundo ${ }^{25}$. Primeiro

21 Compare-se A19/B33, onde "intuição" (Anschauung) é definida como o que é imediato em nosso conhecimento (a saber, relação imediata de nosso conhecimento com os objetos), com A320/B377, onde se diz que a "intuição" (Anschauung) é uma subespécie do gênero representação (Vorstellung).

22 Muito embora o único que explicitamente levasse a cabo uma versão dessa teoria fosse C. L. Reinhold (Versuch einer neuen Theorie des menschlichen Vorstellungsvermögens, 1789).

23 Cf. A1-2 com B1-2 ("Von dem Unterschide der reinen und empirischen Erkenntnis"). Sobre isso ver Bird (2006, p. 105-6), 126ss; Lisa Shabel (2010, p. 95ss).

24 Consistindo numa série de observações metodológicas, definições conceituais e consequências que Kant extrai da primeira parte, bem como de outras conclusões e análises que não decorrem diretamente da primeira parte, mas que devem ser tratadas na Metafísica a partir da nova metodologia que Kant propõe; como, por exemplo, o problema da liberdade e a teoria dos postulados. Sobre isso, veja-se Bird (2006, p. 739ss).

25 Veja-se, por exemplo, o que Kant diz em A20-1/B34-5. 
as da percepção ${ }^{26}$, depois as da inteligência ${ }^{27}$, e por fim as da razão propriamente dita ${ }^{28}$ : trata-se por isso de uma teoria que discrimina e analisa separadamente cada tipo de estrutura e depois mostra como se articula com as outras, a fim de configurar a arcabouço formal que condiciona ou preside toda a cognição e o raciocínio humanos; o que acaba por revelar a forma de toda a experiência que possa ser considerada conhecimento de objetos de percepção atual ou possível (e mesmo como forma lógica de todo o pensamento dos entes que não são objeto de percepção). Por isso, a teoria é transcendental, a saber, porque investiga todas e cada uma das estruturas que devemos admitir como conditiones sine que non da nossa experiência; que de certo modo, portanto, "transcendem" a experiência dos dados sensoriais do nosso conhecimento. Nesse sentido, a metafísica de Kant, também chamada por muitos de "metafísica da experiência", é fundamentalmente "filosofia transcendental"29. A própria Crítica da razão pura acaba por identificar-se, ao menos parcialmente, à filosofia transcendental ${ }^{30}$.

${ }^{26}$ Que é a tarefa da Estética conforme o que Kant anuncia em KrV A22/B36.

27 O que Kant passa a fazer a partir de A65-6/B90-1.

${ }^{28}$ Kant faz isso em vários passos na Dialética transcendental, logo após a exposição de sua teoria da ilusão transcendental (A293/B349ss), a começar pelo Livro Primeiro da Dialética Transcendental (A310ss/B367ss).

29 A saber, aquela que investiga, classifica e demontra nosso modo de conhecer objetos. Veja-se, por exemplo, KrV A11: "Ich nenne alle Erkenntniß transscendental, die sich nicht sowohl mit Gegenständen, sondern mit unsern Begriffen a priori von Gegenständen überhaupt beschäftigt. Ein System solcher Begriffe würde Transscendental-Philosophie heißen”. Em KrV B25 Kant parece alargar a acepção para não deixar de fora as intuições a priori do espaço e do tempo, o que a definição de A parecia negligenciar: "Ich nenne alle Erkenntniß transscendental, die sich nicht sowohl mit Gegenständen, sondern mit unserer Erkenntnißart von Gegenständen, so fern diese a priori möglich sein soll, überhaupt beschäftigt." Sobre esse aspecto, e sobre a ideia de filosofia transcendental como metafísica e ontologia do ser sensível, veja-se Portela, 2001. Essa noção sugere por sua vez um parentesco com a chamada "metafísica da experiência", termo que parece ter sido cunhado por Paton (1936, 2 vols.), e provavelmente popularizado por Strawson (1966, p. 24).

30 Mesmo que em A11/B25 tenha sido caracterizada como propedêtica ao sistema completo de todos os conhecimentos da razão pura, Kant acaba por identificá-la parcialmente à filosofia transcendental (em A13-4/B27-8 explica que a identificação não é completa porque o sistema deverá conter uma análise completa de todo o conhecimento a priori, tanto analítico como sintético) (Sobre isso, veja-se Portela 2001). Assim, em A14-5/B28 


\section{A estrutura metódica da primeira Crítica}

Entrementes, a subdivisão da teoria transcendental dos elementos segue em parte uma tradição neoaristotélica que Kant recebe da Schulphilosophie (Escolástica alemã), mas em boa medida altera. Essa tradição subdividia a parte do Organon aristotélico que tratava dos princípios do conhecimento e da demonstração em Analítica e Dialética ${ }^{31}$. Porém, à Analítica Kant antepõe uma Estética, o que é uma novidade; e então divide a primeira parte da Crítica em Estética e Lógica. Essa última, por sua vez, subdivide-a em Analítica e Dialética, conforme a tradição escolástica ${ }^{32}$. De modo que a teoria transcendental dos elementos subdivide-se em: 1) Estética ou teoria das estruturas da percepção (espaço e tempo como intuições a priori e formas puras de intuição); 2) Analítica

afirma que: "Zur Kritik der reinen Vernunft gehört demnach alles, was die TransscendentalPhilosophie ausmacht, und sie ist die vollständige Idee der Transscendental-Philosophie, aber diese Wissenschaft noch nicht selbst, weil sie in der Analysis nur so weit geht, als es zur vollständigen Beurtheilung der synthetischen Erkenntniß a priori erforderlich ist" (Cf. ainda com A841/B869, onde a Kritik é parcialmente identificada à Metafísica). Além disso, algumas reflexões oriundas da década silenciosa e da época da edição A parecem corroborar a identificação entre a crítica e a filosofia transcendental, por exemplo: R. 4897 (AA 18:22), R. 5127 (18:99-100), R. 5133 (18:101). Outras Reflexionen sugerem pelo menos uma relação intrínseca, ou muito próxima, entre ambas: R. 4889 (18:20), R. 4890 (18:20), R. 5070 (18: 78-9), R. 5083 (18:82), R. 5667 (18:323). Posteriormente, sobretudo de 1788 em diante, Kant estende o escopo da filosofia transcendental e da crítica da razão em geral aos domínios da metafísica da física, da ação moral e técnica, e da reflexão teleológica, os quais são respectivamente cobertos pelos Princípios Metafísicos da Ciência Natural, pela segunda e pela terceira Críticas, e pela Metafísica dos Costumes.

31 Por "Organon" me refiro aos escritos lógicos de Aristóteles recolhidos pela tradição: Categorias, Da Interpretação, Primeiros e Segundos Analíticos, Tópicos e Refutações Sofísticas. Os últimos dois escritos seriam "dialéticos", sobretudo o primeiro, por tratarem do "método dialético", referindo-se a raciocínios que partem de opiniões dadas ou ideias admitidas (ex endóxon) e levam por isso a conclusões prováveis. Sobre isso, veja-se: Alcoforado (1993, p. 9-31).

32 Sobre isso e aspectos correlatos da concepção kantiana de Lógica, veja-se o clássico estudo de Giorgio Tonelli, "Der historische Ursprung der Kantischen Termini ,Analytik' und ,Dialektik"' (1962, p. 120-139). Veja-se ainda de Tonelli Kant's Critique of Pure Reason Within the Tradition of Modern Logic (1994). Ver também Riccardo Pozzo (2004, p. 173-192). Sobre a relação entre Estética e Analítica, veja-se François Xavier Chenet (1994, p. 15ss, 399s, 406ss); Falkenstein (1995, p. 21ss). Sobre a Estética como uma defesa da sensibilidade de Kant, veja-se: L. Ribeiro dos Santos (1994). 
ou teoria das estruturas ou formas puras da inteligência ou compreensão, a saber: (i) as categorias como conceitos a priori de objetos em geral, na Analítica dos conceitos, (ii) os schemata como categorias referidas a um domínio temporal, junto aos Princípios resultantes da sua aplicação enquanto juízos referidos a priori a objetos espácio-temporais (i. é, juízos "sintéticos a priori"), na Analítica dos princípios; e por fim, 3) Dialética, ou teoria acerca dos princípios racionais de concepção e dedução (as ideias da razão e as inferências mediatas que elas possibilitam), e das falácias decorrentes da confusão do estatuto lógico e regulativo das ideias com conceitos ontológicos e constitutivos de objetos supostamente inteligíveis.

$\mathrm{Na}$ verdade, é precisamente em virtude dos argumentos contidos nessa última (3) parte da Crítica da razão pura que a filosofia transcendental apresentada por Kant pode ser propriamente considerada "filosofia crítica" 33: pois o argumento central acima reconstruído, segundo o qual o conhecimento metafísico deve ser caracterizado como conhecimento a priori de objetos, mas não como "conhecimento de objetos a priori", embora seja apresentado sumariamente no Prefácio e na Introdução, somente encontra seu solo, sua raiz e sua justificação detalhada como uma crítica da razão pura na formulação de uma teoria da ilusão transcendental (A293/B349ss), na análise da doutrina das ideias da razão pura (A312/ B369ss; e também no Apêndice: A642/B670ss) e, sobretudo, na crítica específica de cada um dos paralogismos da psicologia racional (A341/ B399ss), das antinomias da cosmologia racional (A405/B432ss), e dos sofismas da teologia racional (A583/B611ss). Analogamente, é preciso dizer também que aquilo que caracteriza primeiramente a empresa kantiana como uma "filosofia transcendental", a saber, como meta-teoria acerca das estruturas que a priori condicionam e possibilitam tanto a concepção como a percepção e o conhecimento dos objetos do mundo na experiência e na ciência, é principalmente a análise empreendida na Estética e na Analítica transcendentais ${ }^{34}$.

\footnotetext{
33 Naturalmente, essa alegação ganha sentido sob a suposição de que a parte negativa ou destrutiva da empresa kantiana equivale à crítica da razão metafísica, e que a filosofia transcendental constitui sua proposta positiva ou construtiva para uma nova metafísica científica.

34 Que, de acordo com alguns textos das Vorlesungen, caracterizariam em conjunto a "ontologia" kantiana: Metaphysik von Schön ( AA 28: 470), Metaphysik Dohna AA 28:
} 
A Estética transcendental, todavia, é o lugar onde Kant primeiro demonstra tanto a possibilidade de um conhecimento a priori dos objetos (aspecto "transcendental"), quanto a impossibilidade de um conhecimento das coisas em si mesmas (i. é, de objetos a priori), que é propriamente o aspecto "crítico" ${ }^{35}$. Desse modo, pode-se dizer que na Estética transcendental confluem num mesmo ponto o sentido crítico e o sentido transcendental da investigação metafísica de Kant ${ }^{36}$. Poder-se-ia dizer que

617) (Apud Chenet, p. 25). Mas mostrei em outro lugar que há outros textos críticos (p. ex., AA 05: 181), do espólio e das Vorlesungen que apontam mais para a Analítica como o lugar da ontologia formal kantiana [por exemplo, R. 4152 (AA 17: 436); R. 5130-5131 (AA 18: 100); R. 5603 (AA 18: 247); R. 5936 (AA 18: 394); Met. Dohna, AA 28: 616-617; Met. K2, AA 28: 714; Met. L1, AA 28: 185; Fortschritte, AA 20: 315].

$35 \mathrm{Na}$ verdade Kant ensina que não devemos nos referir indistintamente ao conhecimento das "coisas em geral" (a expressão é, no mais das vezes, Dinge überhaupt", por exemplo, em A 35/B51, B298, B303ss,B327-8), como se a priori pudéssemos conhecer as coisas tal como elas seriam em si mesmas, como por um ato de conhecimento intelectual imediato. Antes devemos introduzir uma distinção no interior do conceito de coisa em geral: as coisas empíricas devem ser consideradas "fenômenos" na medida em que são ou podem ser conhecidas na experiência como objetos do entendimento e dos sentidos, e submetidos a suas respectivas condições, e como "coisas em si mesmas" apenas na medida em que as consideramos em abstração da maneira como as conhecemos, i. é, na medida em que as pensamos como entes que não conhecemos (cf. por exemplo, BXIXss, sobretudo B XXIIInota; BXXV-XXVIII; A27/B43ss). É justamente essa presunção de acesso ao conhecimento de coisas em si mesmas que conduz à ideia de que poderíamos conhecer objetos inteligíveis, puros ou a priori. Sobre a crítica à metafísica wolfiana por partir do conceito de coisa, veja-se a Metafísica Dohna, AA 28:615-616.

36 Cabe, não obstante, uma observação sobre o sentido dado por Kant ao termo "crítica" e "crítica da razão pura": Na primeira edição, já no prefácio, Kant apresentava inicialmente a Crítica (Kritik) como uma crítica da faculdade cognitiva humana em seu uso puro segundo leis eternas e imutáveis (AXII). No prefácio à segunda edição acrescentava que se trata de um tratado do método da Metafísica, não de seu sistema definitivo (BXXII). Na introdução acrescentava que a Crítica seria a ciência propedêutica a traçar o plano e constituir a ideia da Filosofia Transcendental entendida como um sistema de todo o conhecimento a priori, mas não se identificaria com aquela por não executar ainda uma análise completa de todo o conhecimento a priori (em A13-14/B24ss) "Zur Kritik der reinen Vernunft gehört demnach alles, was die Transscendental-Philosophie ausmacht, und sie ist die vollständige Idee der Transscendental-Philosophie, aber diese Wissenschaft noch nicht selbst, weil sie in der Analysis nur so weit geht, als es zur vollständigen Beurtheilung der synthetischen Erkenntniß a priori erforderlich ist". Essa ideia é retomada e aprofundada como a ideia de uma ciência que investiga as fontes dos conhecimentos a priori para poder julgar e decidir acerca das pretensões e dos limites do conhecimento por razão pura; e desse modo não constitui um sistema metafísico doutrinário, como na metafísica tradicional, mas uma crítica 
o lugar da Estética transcendental define a parte da ciência que determina as estruturas formais que condicionam a nossa percepção dos objetos da experiência. Nesse sentido, sua finalidade consistiria tanto na formulação e defesa de uma teoria da percepção a priori como um dos elementos básicos para uma teoria geral do conhecimento racional, quanto na recusa de um conhecimento matemático ou metafísico de objetos racionais puros.

A Analítica, por sua vez, ocupa-se deliberadamente do aspecto transcendental propriamente dito. Com efeito, na Analítica Kant investiga, descobre, elenca e demonstra como as formas categoriais do pensamento constituem a estrutura formal dos objetos que podemos pensar e conhecer, e oferece um critério de distinção entre ambos esses domínios ao restringir a aplicação das formas da nossa inteligência ao domínio da percepção, conjugando, assim, o resultado da Estética com o da Analítica. Nesse sentido, a Analítica apresenta uma ontologia formal, no sentido geral de una teoria a priori dos objetos: uma teoria categorial que opera una reconstrução meta-teórica da estrutura formal objetiva de nosso mundo a partir da estrutura de nosso pensamento e de nossas faculdades cognitivas.

Embora isso tenha consequências epistêmicas e semânticas importantes, aqui não se trata de categorias enquanto meros conceitos de objetos, no sentido de representações discursivas ou regras de identificação

da especulação e dos erros da Metafísica ("eine Wissenschaft der bloßen Beurtheilung der reinen Vernunft, ihrer Quellen und Grenzen als die Propädeutik zum System der reinen Vernunft (...). Eine solche würde nicht eine Doctrin, sondern nur Kritik der reinen Vernunft heißen müssen, und ihr Nutzen würde in Ansehung der Speculation wirklich nur negativ sein, nicht zur Erweiterung, sondern nur zur Läuterung unserer Vernunft dienen und sie von Irrthümern frei halten, welches schon sehr viel gewonnen ist" (B24) ). Essa crítica, além disso, chama-se "transcendental" porque investiga os princípios do conhecimento a priori e determina quando são aplicados de modo legítimo ou ilegítimo: "Diese Untersuchung, die wir eigentlich nicht Doctrin, sondern nur transscendentale Kritik nennen können, weil sie nicht die Erweiterung der Erkenntnisse selbst, sondern nur die Berichtigung derselben zur Absicht hat und den Probirstein des Werths oder Unwerths aller Erkenntnisse a priori abgeben soll, ist das, womit wir uns jetzt beschäftigen. Eine solche Kritik ist demnach eine Vorbereitung wo möglich zu einem Organon, und wenn dieses nicht gelingen sollte, wenigstens zu einem Kanon derselben, nach welchem allenfalls dereinst das vollständige System der Philosophie der reinen Vernunft, es mag nun in Erweiterung oder bloßer Begrenzung ihrer Erkenntniß bestehen, sowohl analytisch als synthetisch dargestellt werden könnte" (A12/B26). Cf. B746ss. 
como termos singulares, definições ou descrições. Justamente, o que permite caracterizar os chamados "conceitos puros" do entendimento como "categorias" é o fato de que não são conceitos como quaisquer outros, porque contêm um "conteúdo transcendental", a saber, a forma lógica de todo objeto. Trata-se antes de formas primitivas, universais e necessárias ("funções de síntese") que constituem "objetos" a partir de sequências de um input que em si mesmo é não referencial. Tampouco se trata de simples funções de julgar, nem de meras condições epistêmicas, mas antes de predicados ontológicos (KU AA 5: 181) que constituem a priori a estrutura da objetualidade dos "objetos" que compõem o inventário de nosso universo em geral, e do universo espácio-temporal como um caso particular no qual o conhecimento é possível e efetivo. Por categoria Kant entende uma estrutura adquirida e construída a priori por ocasião de input, que designa o modo em que tudo que pode ser pensado e conhecido pode de fato ser pensado e conhecido como "objeto". Essas são as condições não-empíricas de toda a empiria e de todo o pensamento que a Analítica dos conceitos apresenta. Quanto aos princípios do entendimento puro, não são apenas proposições de caráter epistemológico, i. é, meras condições da objetividade de nossos juízos. Pois, na medida que supõem a aplicação de categorias esquematizadas, representam também e sobretudo a estrutura formal de todos os "objetos" que podem ser objeto de experiência possível, a saber, fenômenos espácio-temporais (como Kant diz: "as condições necessárias da unidade sintética do múltiple da intuição em uma experiência possível":A158/B197).

Desse modo, penso que se a epistemologia kantiana pressupõe uma "semântica a priori" de todos os juízos sobre objetos que podemos conhecer a partir dos princípios do entendimento puro, essa última pareceria, por sua vez, ser uma consequência do modo como nossa mente e nossas capacidades cognitivas estruturam a priori o mundo como um "mundo de objetos". Numa palavra: é claro que problemas de epistemologia e semântica estão presentes no projeto kantiano, mas o que a Analítica faz primeiro é construir uma ontologia formal para garantir o solo de uma metafísica científica, capaz de obter conhecimento puro e legítimo de acordo com nossas capacidades e aptidões cognitivas humanas. Portanto, uma meta- 
teoria dos objetos que requer como complemento uma justificação para mostrar que esses conceitos puros não ultrapassam nossa capacidade e são condições universais e necessárias de todos objetos que podemos pensar (objetos ${ }^{1}$ ) e de todos os que podemos conhecer (objetos ${ }^{2}$ ), ao combinar o resultado da Estética ao da Analítica.

A Dialética, por fim, em termos gerais investiga as inferências metafísicas ("dialéticas") baseadas em juízos acerca de coisas em si mesmas, coisas que podemos conceber como (objetos $\left.{ }^{1}\right)$, mas não podemos intuir nem conhecer propriamente como $\left(\text { objetos }^{2}\right)^{37}$. Esses objetos "a priori” são os da psicologia, da cosmologia e da teologia da metafísica racionalista: nossa alma, o universo, Deus.

Além disso, como meio para justificar a impossibilidade do conhecimento desses "objetos" (objetos ${ }^{1}$ ), Kant argumenta na Dialética que certas regras lógicas são confundidas com propriedades de coisas em si, ou com coisas em si mesmas, e apresenta uma teoria sobre a estrutura e a função da razão em toda cognição, em decorrência dos resultados da Estética e da Analítica. A partir dessa teoria, Kant explica que há muitas coisas que podemos pensar, mas não conhecer; que há certas coisas que podemos e devemos pensar, embora não possamos conhecer; e que conceitos racionais puros não possuem função ontológica, mas antes servem de critério formal para a aplicação de categorias na experiência.

Kant sugere que ideias possuem uma função normativa específica na unificação sistemática dos conhecimentos e por isso operam como critérios de intelecção, raciocínio e ação (já que ideias operam como ideais normativos). Mas a explicação pontual do caráter específico do uso lógico, metafísico e prático das ideias como princípios racionais puros mereceria um esclarecimento ulterior que foge ao escopo de um discurso introdutório e preliminar acerca do projeto kantiano ${ }^{38}$.

\footnotetext{
37 Trata-se de "objetos a priori", portanto, entendidos como subclasse dos "objetos" (já que estes últimos, bem entendidos, seriam meras estruturas formais de intelecção, viz. funções de unidade de representações intuitivas possíveis).

38 Ofereci uma caracterização preliminar da Dialética transcendental e do seu escopo na Crítica da razão pura em meu A Dialética em Kant e Hegel (BONACCINI, 2000, p. 31101, especialmente p. 51ss).
} 


\section{Referências}

ALCOFORADO, P. Roteiro para o estudo do Órganon, Educação e Filosofia, Uberlândia, v. 7, n. 13, p. 9-31. 1993.

BIRD, G. The Revolutionary Kant. La Salle: Open Court, 2006.

BONACCINI, J. A. Anotações sobre a Metafísica Dohna. Philosophica, Lisboa, n. 30, p. 225-243. 2007.

. Kant e o problema da coisa em si no Idealismo Alemão, Rio de Janeiro: Relume Dumará, 2003.

. A Dialética em Kant e Hegel. Natal: EDUFRN, 2000.

CAIMI, M. Leçons sur Kant. La déduction transcendantale dans la deuxiène édition de la Critique de la raison pure. Paris: Publications de la Sorbonne, 2007.

CHENET, F. X. L'assise de l'ontologie critique: L'Esthétique transcendantale. Lille: Presses Universitaires de Lille, 1994.

FALKENSTEIN, L. Kant's Intuitionism, A Commentary on the Transcendental Aesthetic. University of Toronto Press: Toronto, 1995.

KANT. I. Kants Gesammelte Schriften. Herausgegeben von der Königlichen Preussischen Akademie der Wissenschaften (Berlin: G. Reimer. 1902-ff.); Königlichen Preussischen u. Deutschen Akademie der Wissenschaften. Berlin: W. De Gruyter. 1922-ff. (29 vols.)

Kritik der reinen Vernunft. Nach der ersten und zweiten OriginalAusgabe neu herausgegeben von Raymund Schmidt. Hamburg: F. Meiner, 1956 (Durchgesehener Nachdruck von 1976.)

KITCHER, P. Kant's Transcendental Psychology. Oxford: Oxford University Press, 1990.

LANDIM FILHO, R. Descartes: "idealista empírico e realista transcendental"?, Sintese-Nova Fase, v. 23, n. 74, p. 313-343. 1993.

LOPARIC, Z. A Semântica Transcendental de Kant. Campinas, Brazil: UNICAMP, Centro de Lógica, Epistemologia e História da Ciência, 2000. PARSONS, C. The Transcendental Aesthetic, In: GUYER, P. (Ed.). The 
Cambridge Companion to Kant, Cambridge: Cambridge University Press, 1992.

PATON, H. J. Kant's metaphysic of experience. A commentary on the first half of the Kritik der reinen Vernunft. London: N. York; Allen \& Unwin, 1936, 2vols.

PORTElA, L. C. Yanzer, Por que a Crítica da razão pura é uma Metafisica? Ensaio de uma defesa. 2001. Dissertação (Mestrado em Filosofia) - Faculdade de Filosofia, Universidade Federal da Paraíba, João Pessoa, 2001.

POZZO, R. Kant on Five Intellectual Virtues, In: POZZO, R. (Ed.). The Impact of Aristotelianism on Modern Philosophy, Studies in Philosophy and the History of Philosophy, v. 39, Catholic University of America Press, 2004. p. 173-192.

PRAUSS, G. Kant und das Problem der Dinge an sich. Bonn: Bouvier, 1989 [1973].

REINHOLD, C. L. Versuch einer neuen Theorie des menschlichen Vorstellungsvermögens. Prag u. Jena: C. Widtmann \& J.M. Mauke,1789.

RIBEIRO, dos Santos, L. A Razão Sensível, Estudos Kantianos. Lisboa: Colibri, 1994.

SHABEL, L. The Transcendental Aesthetic. In: GUYER, P. (Ed.). The Cambridge Companion to Kant's Critique of pure Reason. Cambridge: Cambridge University Press, 2010.

SCHÖNRICH, G. Kategorien und transzendentale Argumentation: Kant und die Idee einer transzendentalen Semiotik, Frankfurt a/M: Suhrkamp, 1981.

STRAWSON, P. F. The Bounds of Sense: An Essay on Kant's Critique of Pure Reason, London: Methuen \& Co, 1966.

TONELLI, G. Der historische Ursprung der Kantischen Termini, "Analytik" und "Dialektik", In: Rothaker, E. (Hrsg.). Archiv für Begriffsgeschichte. Bausteine zu einem Historischen Wörterbuch der Philosophie. Hrsg. im Auftrage der Kommission für Philosophie der Akademie der Wissenschaften und der Literatur zu Mainz, v. 7. Bonn: Bouvier, 1962. 
. Kant's Critique of Pure Reason Within the Tradition of Modern Logic (Ed. by David H. Chandler), Studien und Materialien zur Geschichte der Philosophie, Olms: Hildesheim, 1994.

VAIHINGER, H. Kommentar zu Kants Kritik der reinen Vernunft [I, 1881; II, 1892], hrsg. von R. Schmidt, Scientia: AAlen, 1970 (Neudruck der 2. Aufl. Stuttgart: Union Deutsche Verlagsgesellschaft).

Data de registro:27/05/2013

Data de aceite: 08/07/2013 